\title{
Effective ways of finding Adverse Drug Reactions in Pharmacovigilance
}

\author{
Kamatchi Sankar, Latha Parthiban
}

\begin{abstract}
With many adverse effects happening on population due to medic al drugs, there is driving need to find these effects and reduce it. Hence researchers are working on FDA_AERS, a real time database to find the adverse effect present in drugs. This field has developed as pharmacovigilance and data mining algorithm helps in improving the accuracy of clinical analysis. In this paper, growth of Pharmacovigilance in India and a novel way to find adverse drug reaction is proposed
\end{abstract}

Index Terms: Pharmacovigilance, Data mining, Adverse Events

\section{INTRODUCTION}

Pharmacovigilance aims at the best use of medicine to cure the disease with no adverse effects. Pharmacovigilance deals with science and activities relating to the identification, analysis and stoppage of ADRs. So each country has "Safety monitoring of medicinal products-guidelines for setting up and running a pharmacovigilance centre" with aim to observe ADRs.

The aim of PvPI is to gather, assemble and investigate the data and recommend their results to corresponding authorities. The organization of paper is as follows: Section 2 describes the literature survey; section 3 discusses on effective Pharmacovigilance; section 4 discusses on data mining algorithm for Pharmacovigilance; section 5 the conclusions.

\section{LITERATURE REVIEW}

Because of the boundaries of clinical trials done before entering into market, adverse events due to a specific drug cannot be assessed before its release [2]. Table 1 shows the report on year wise FDA dataset. Literature revealed that adverse reactions in drugs released to public has millions of death and hospitalization [3-19]. Pharmacovigilance becomes necessary to identify these ADRs [20-28]. Hence, present research focus is for ADR detection

As information from single source has many limitations, present research focused on gathering information from multiple sources. Figure 1 shows pharmacovigilance in different stages of drug development which can be divided into premarket and post market analysis which can be divided into many phases

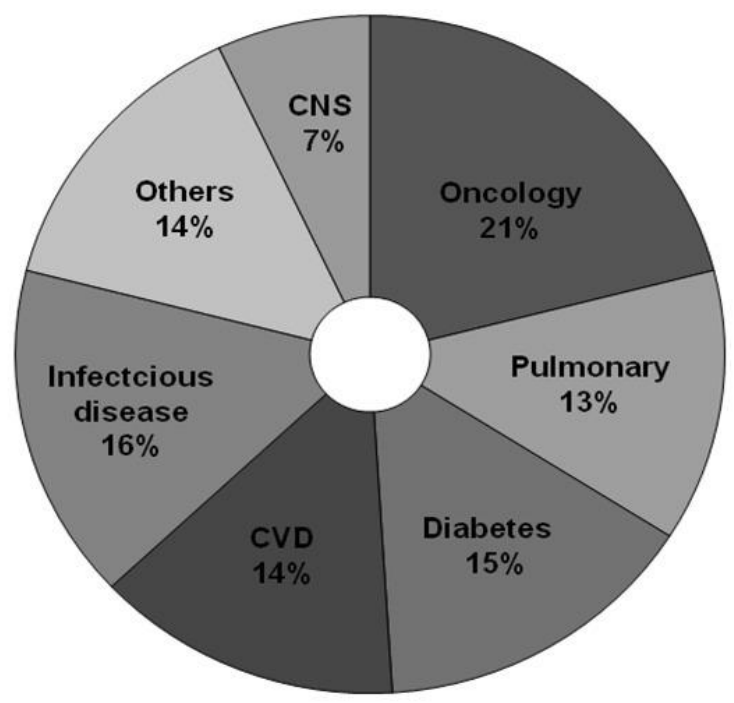

Fig. 2 Clinical trials in India

Distribution of clinical trials throughout India and presence of different patient strength is shown in Fig. 2 [18].

\section{EFFECTIVE PHARMACOVIGILANCE PROCEEDURE}

For doing Pharmacovigilance effectively, the timelines for reporting ADRs is shown in Fig 3. The timelines for periodic safety updates reports is shown in Fig 4.

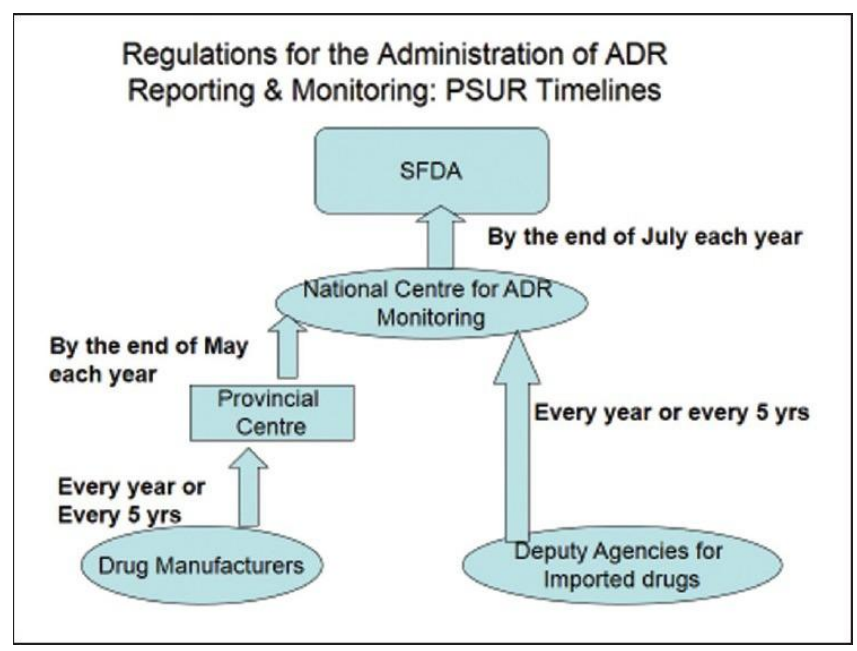

Fig 4 Timelines for periodic safety updates reports

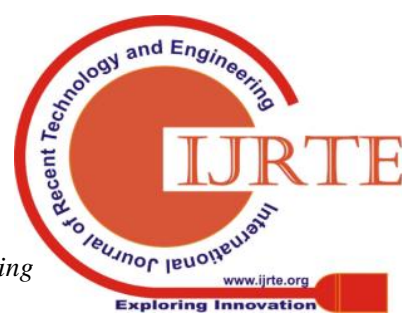




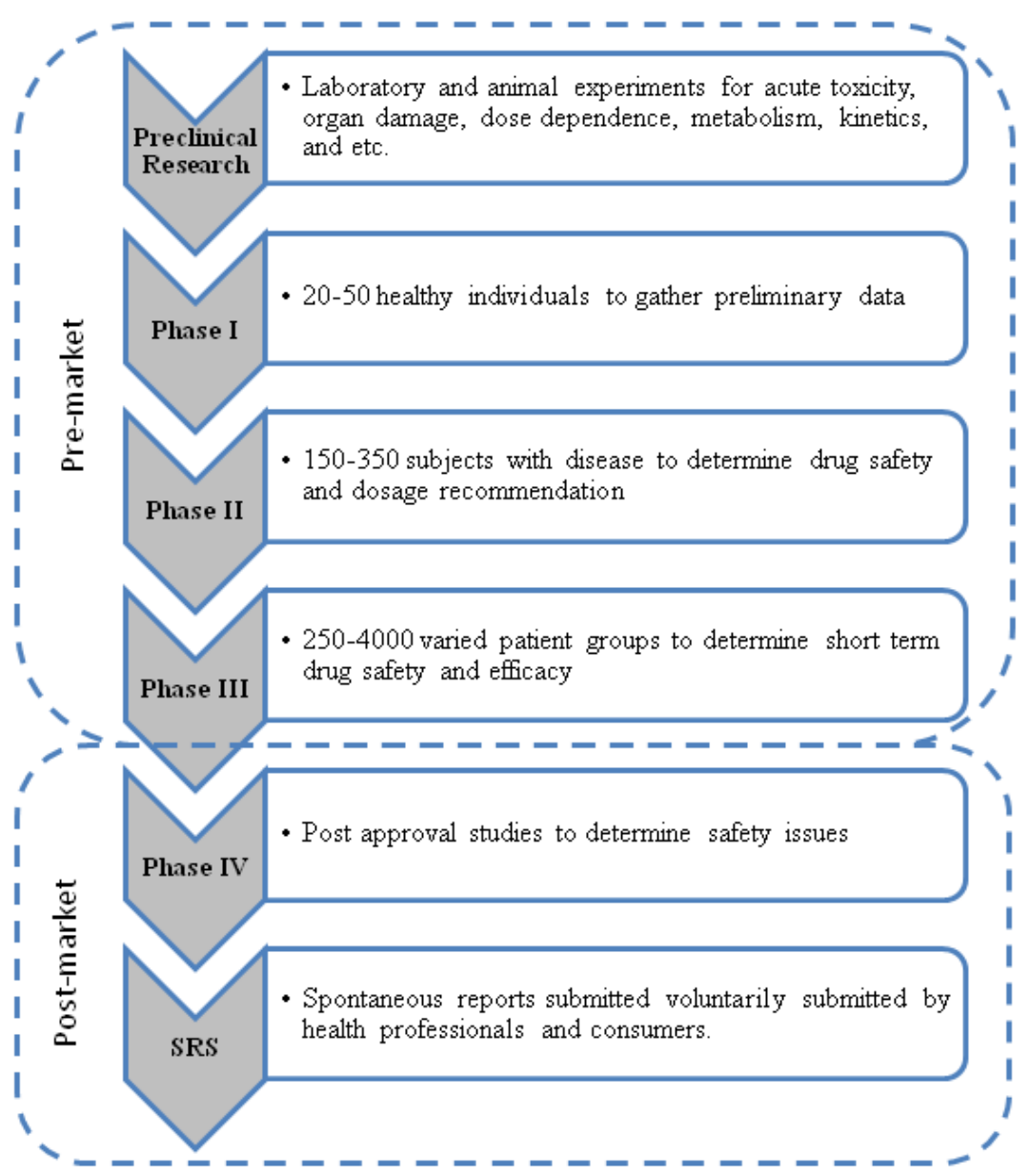

Fig 1 Pharmacovigilance in different stages of drug development

\section{Regulations for the Administration of ADR Reporting \& Monitoring: Procedure \& Timeliness}

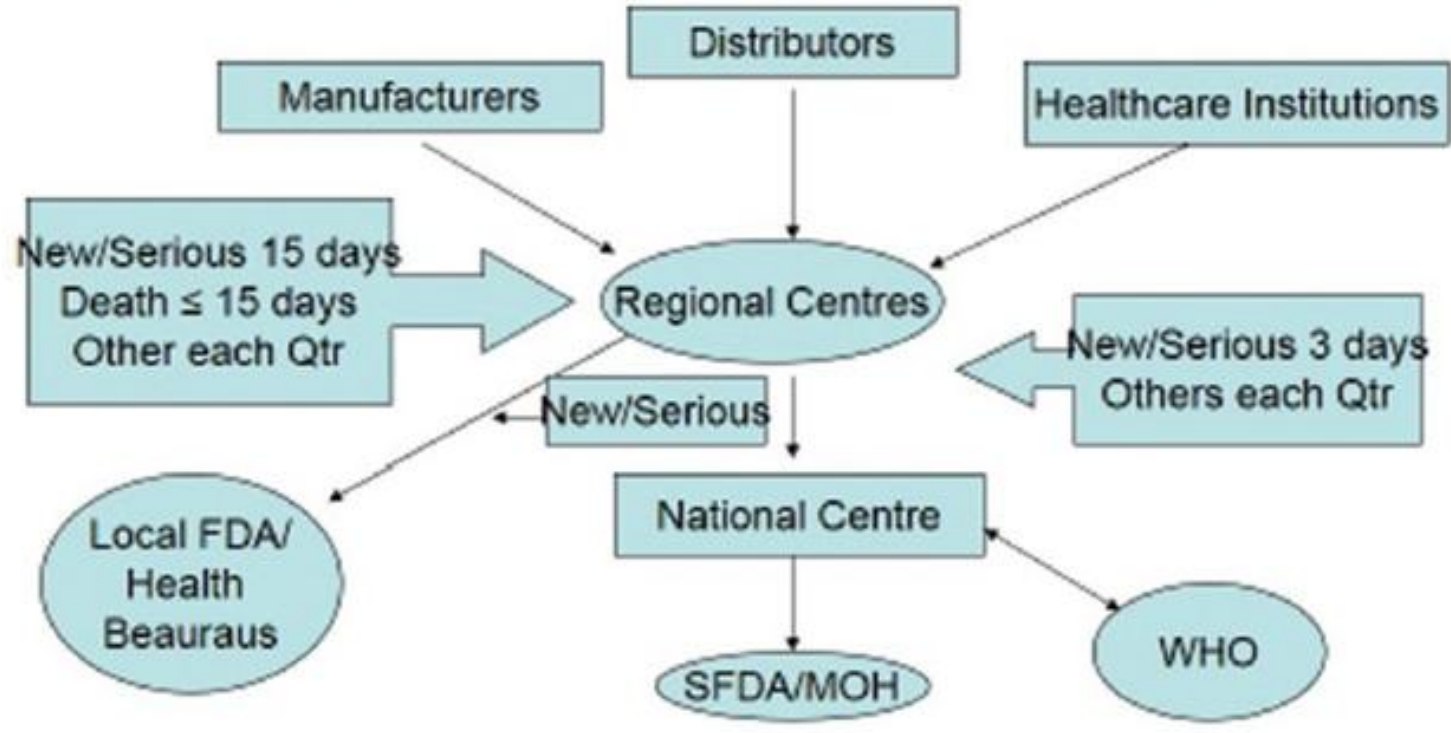

Fig 3 Timelines for reporting ADRs 
International Journal of Recent Technology and Engineering (IJRTE)

ISSN: 2277-3878, Volume-8 Issue-2S4, July 2019

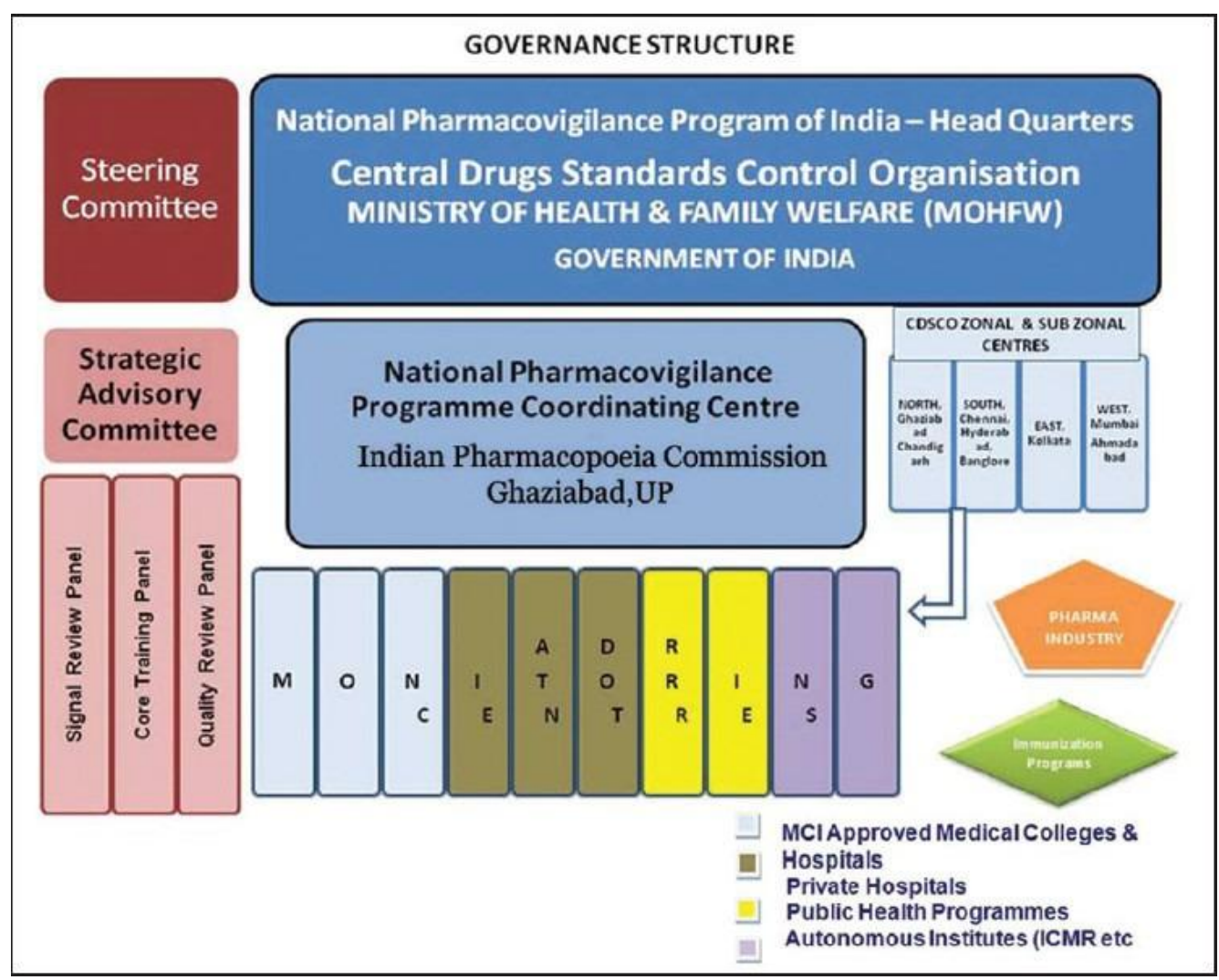

Fig 5 Pharmacovigilance structure in India

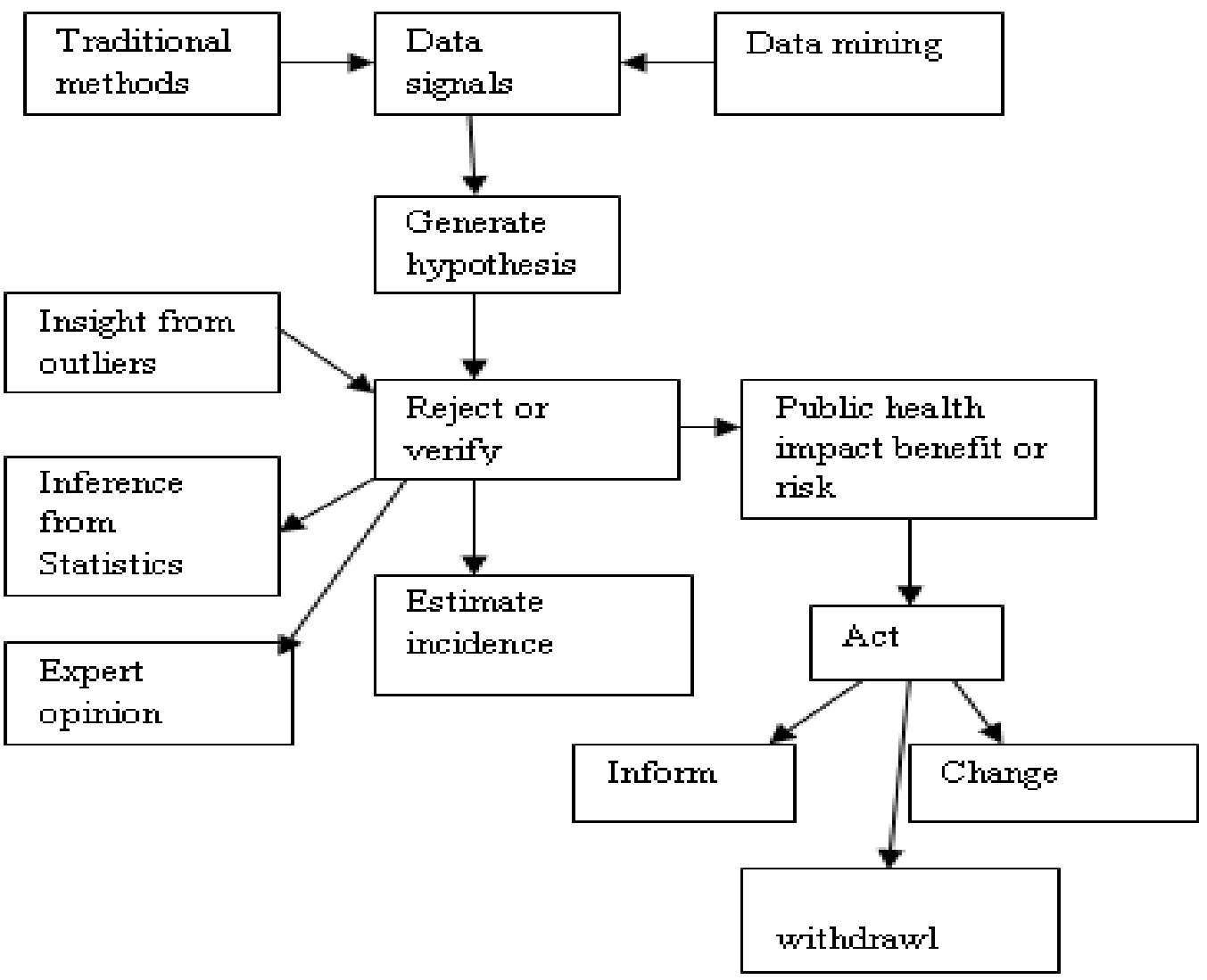

Fig 6 Information flow in Pharmacovigilance

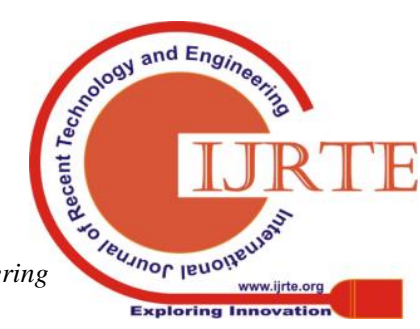


Fig 5 shoes the present pharmacovigilance structure in India which has monitoring facility over MCI approved medical colleges and hospitals all over India.

\section{DATA MINING ALGORITHMS FOR PHARMACOVIGILANCE}

The class label attribute output disease had two distinct values (Yes, No) represented by hypothesis $(\mathrm{H})$.

$$
\mathrm{P}(\mathrm{H} / \mathrm{X})=\frac{\mathrm{P}(\mathrm{X} / \mathrm{H}) \times \mathrm{P}(\mathrm{H})}{\mathrm{P}(\mathrm{X})}
$$

$\mathrm{P}(\mathrm{H} / \mathrm{X})$ is called posterior probability where hypothesis $(\mathrm{H})$ represents the presence of output disease with $\mathrm{X}$ as known disease category and outcome. $P(\mathrm{X} / \mathrm{H})$ represents the posterior probability of $\mathrm{X}$ on the subject of $\mathrm{H} . P(\mathrm{H})$ represents the prior probability of $\mathrm{H}$ irrespective of disease category, drug code and outcome. $\mathrm{P}(\mathrm{X})$ denotes prior probability of $\mathrm{X}$. For calculating $P(\mathrm{X})$, output disease record sets with 'unknown' category were filtered. Then the posterior probability was calculated based on outcome, disease category and drug code. To improve Naive Bayes algorithm use of Influence Factor helps to determine the dependency and was calculated for the attributes drug code, disease category and outcome on the class label.

$$
\mathrm{I}(\mathrm{X} / \mathrm{Ci})=\frac{\mathrm{N}(\mathrm{X} / \mathrm{Ci})}{\mathrm{N}(\mathrm{Ci})}
$$

where $\mathrm{I}(\mathrm{X} / \mathrm{Ci})=$ Influence Factor $\mathrm{N}\left(\mathrm{X} / \mathrm{C}_{\mathrm{i}}\right)$ represents the number of records in which attribute $\mathrm{X}$ had class label $\mathrm{C}_{\mathrm{i}}$ and $\mathrm{N}(\mathrm{Ci})$ represents the total number of records with class label $\mathrm{C}_{\mathrm{i}}$. The dataset was divided based on the class label 'Yes' and 'No'. Influence factor for attributes with high values were taken and others ignored.

As information from single source has many limitations, present research focused on gathering information from multiple sources. Figure 6 shows the information flow in Pharmacovigilance

\section{V.CONCLUSIONS}

With adverse effects on huge population available in FDA_AERS, researchers are looking into new ways in pharmacovigilance. Proper analysis of FDA_AERS can help in saving patients precious life using stable drug safety assistance. Recently, plenty of work has been done to increase the limits of pharmacovigilance. Data mining algorithms helps in improving the accuracy of analysis but overall, results obtained from these algorithms should be measured with care and directed by proper clinical assessment. The work done in this paper will help us to work on missed data and duplicate data removal after which analysis is planned to be done for different adverse effects.

\section{References}

1. Raschi E, Piccinni C, Poluzzi E, Marceline G and De Ponti F, "The association of pancreatitis with antidiabetic drug use: gaining insight through the FDA pharmacovigilance database". Acta Diabetologica, 50(4), 2013, $569-577$.

2. Edwards, I.R. and J.K. Aronson, "Adverse drug reactions: definitions, diagnosis, and management". Lancet, 2000. 356(9237): p. 1255-9.

3. Sanz, E., T. Gomez-Lopez, and M.J. Martinez-Quintas, "Perception ofteratogenic risk of common medicines". Eur J Obstet Gynecol Reprod Biol, 2001. 95(1): p. 127-31.
4. Edwards, I.R., B.-E. Wiholm, and C. Martinez, "Concepts in Risk-Benefit Assess men"t. Drug Safety, 1996. 15(1): p. 1-7.

5. Edwards, I.R., "Spontaneous ADR reporting and drug safety signal induction in perspective". To honour Professor Jens Schou. Pharmacol Toxicol, 2000. 86(Suppl 1): p. 16-19.

6. Edwards, I.R. and B. Hugman, "The challenge of effectively communicating risk-benefit information". Drug Saf, 1997. 17(4): p 216-27.

7. Kellett, N., S.J. Mair, and W.S. Nimmo, "Pre-clinical safety evaluation, in Pharmacovigilance" R. D. Mann and E.B. Andrews, Editors. 2002, John Wiley and Sons, Ltd: Chicester, West Sussex, UK. p. 51-56.

8. Talbot, J.C. and B.S. Nilsson, "Pharmacovigilance in the pharmaceutical indust ry". Br J Clin Pharmacol, 1998. 45(5): p. 427-31.

9. Spilker, B., "Drug Development and Approval Process, in Avery's Drug Treatment", T.M. Speight and N.H.G. Holford, Editors. 1997, Adis International Limited: Auckland. p. 423-449.

10. Amery, W.K., "Why There is a Need for Pharmacovigilance" Pharmacoepidemiol Drug Saf, 1999. 8: p. 61-64.

11. Shapiro, S., "Case control surveillance", in Pharmacoepidemiology, B.L. Strom, Editor. 2000, Churchill Livingstone: New York. p. 15-28,

12. Hurwitz, E.S., et al., "Public Health Service study on Reye's syndrome and medications. Report of the pilot phase" N Engl J Med, 1985. 313(14): p. 849-57.

13. Edwards, I.R. and C. Biriell,":Harmonisation in Pharmacovigilance." Drug Safety, 1994. 10: p. 93-102.

14. Meyboom, R.H., et al., "Principles of signal detection in pharmacovigilance.” Drug Saf, 1997. 16(6): p. 355-65.

15. van Brummulen, P., "Drug Development, in Drug Benefits and Risks", C.J. can Boxtel, B. Santoso, and I.R. Edwards, Editors. 2002, John Wiley and Sons, Limited: Chichester, UK. p. 91-102.

16. Waller, P.C., et al., "Review of company postmarketing surveillance studies". Bmj, 1992. 304(6840): p. 1470-2.

17. Hasford, J. and T. Lamprecht, "Company observational post-marketing studies: drug risk assessment and drug research in special populations--a studybased analysis”. Eur J Clin Pharmacol, 1998. 53(5): p. 369-71.

18. Wood, L., "GPRD in the UK, in Pharmacovigilance", R.D. Mann and E.B. Andrews, Editors. 2002, John Wiley and Sons Ltd: Chichester, UK. p. 373- 378

19. Strom, B.L., "How Should One Perform Pharmacoepidemiological Studies? Choosing Among the Available Alternatives, in Pharmacoepidemiology", B.L. Strom, Editor. 1994, Churchill Livingstone: New York. p. 337-350.

20. Bortnichak, E.A., et al., "Proactive safety surveillance." Pharmacoepidemiol Drug Saf, 2001. 10(3): p. 191-6.

21. Coulter, D.M., "Signal generation in the New Zealand Intensive Medicines Monitoring Programme: a combined clinical and statistical approach”. Drug Saf, 2002. 25(6): p. 433-9.

22. Heeley, E., L.V. Wilton, and S.A. Shakir, "Automated signal generation in prescription-event monitoring”. Drug Saf, 2002. 25(6): p. 423-32.

23. Haramburu, F., et al., "Role of medical journals in adverse drug reactions. II: Uses". British Journal of Clinical Pharmacology, 1988 26(1): p. 7-11. 